\title{
Lawrence Bragg's "Brainwave" Drives Father-Son Collaboration
}

In 1912, some 17 years after the serendipitous discovery of $x$-rays by Wilhelm Röntgen, a debate raged as to the wave or particle nature of this radiation phenomenon. William Henry Bragg, a 50-year-old professor of physics at Leeds University in England, came down firmly on the side of particles, citing the bullet-like nature of the rays, and how they were preferentially scattered in the forward direction when colliding with matter. Max von Laue of Germany, having produced elegant spotdiffraction photographs of CuS by aiming x-rays at crystal samples, used the diffraction behavior as evidence for the wave argument. Experiments by Charles G. Barkla that demonstrated the polarization of $x$-rays confirmed the wave theory in the minds of many scientists. Ironically, it was Bragg's son William Lawrence Bragg (who went by the name of Lawrence) whose burst of insight-a "brainwave," as he called it - settled the argument, at least for the time being. Unfortunately for his father, it was in favor of von Laue and Barkla.

"When I was walking one day along the Backs at Cambridge-I can remember the place behind St. John's College," Lawrence Bragg recalled in The Start of X-ray Analysis, "I suddenly realized that von Laue's spots were the reflections of the x-rays in the sheets of atoms in the crystal." Prior to this realization, von Laue's interpretation was that the patterns were due to a complex set of wavelengths coming from the x-ray tube. Lawrence Bragg announced his insight in the Proceedings of the Cambridge Philosophical Society (November 1912) in a paper titled "The Diffraction of Short Electromagnetic Waves by a Crystal," deliberately avoiding the mention of x-rays to allow his father's theory some hope of surviving. But instead of driving father and son apart, the discovery prompted a rare father-son collaboration that resulted in the awarding of a joint Nobel Prize in Physics for the pair in 1915. For their efforts, von Laue was awarded the Nobel Prize in 1914, and Barkla in 1917.

X-ray diffraction has proven to be a powerful analytical technique for the determination of the atomic structure of a solid. While the symmetry of crystals found in nature was recognized long before the discovery of this technique, the detailed nature of the positions of atoms or ions-their relative locations and spacings-remained a mystery. Chemists spoke of molecules of $\mathrm{NaCl}$ in a solid as if the sodium and the chlorine ions bonded in one-to-one correspondence; indeed, some were upset by the true ionic solid picture when it emerged.

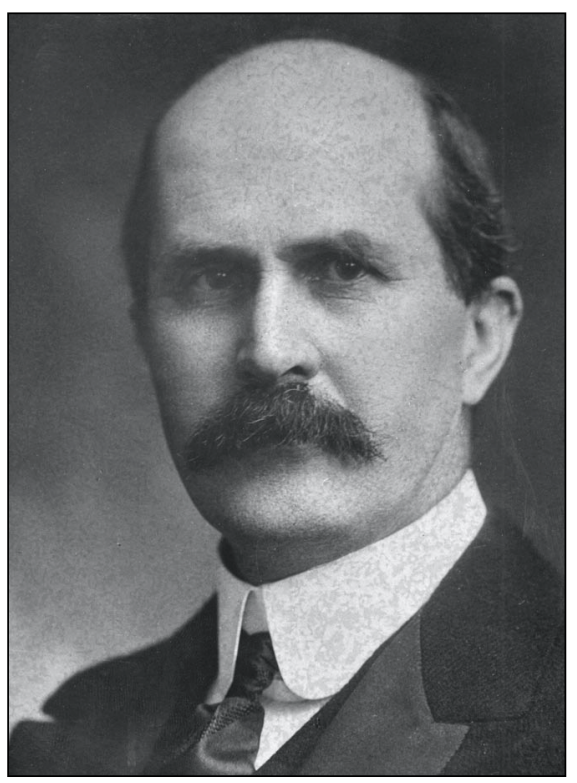

Sir William Henry Bragg. Copyright (C)1915 The Nobel Foundation.

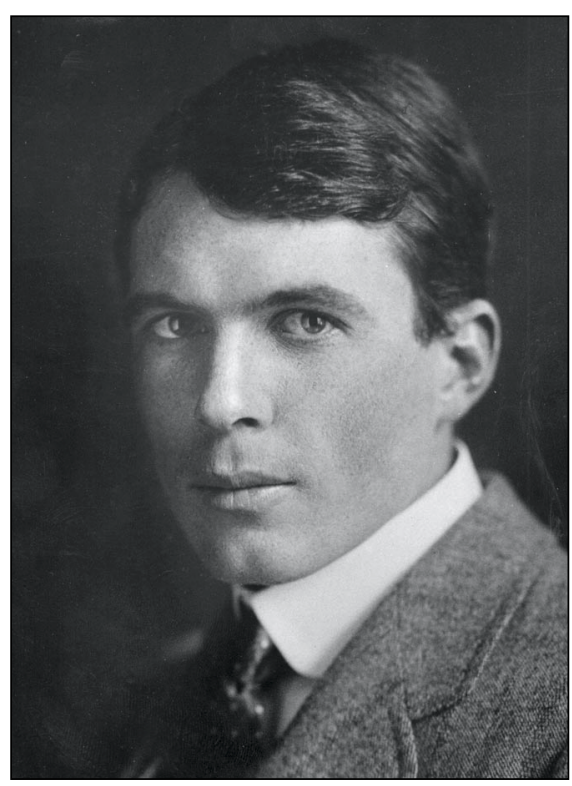

Sir William Lawrence Bragg. Copyright (O)1915 The Nobel Foundation.

William Henry Bragg began his career in Australia as the Professor of Mathematics and Physics at Adelaide University in 1894, with an excellent background in mathematics but none in physics. In 1904, having been elected president of the physics section of the Australian Association for the Advancement of Science, he chose the topic of radioactivity for a speech to the members and quickly began to learn what he could on the subject.

Until this point in his life, at age 42 , William later recalled, "It had never entered my head that I should do any research work." His curiosity aroused by his reading on radiation, he soon obtained some radium samples and began the experiments that were to make him a leading figure in radiation theory in a few years' time. He quickly developed novel hypotheses about the nature of radioactivity. The penetrating power of x-rays, and the fact that they are not deflected by a magnetic field, were accounted for by the "neutral pair hypothesis," which stated that x-rays consisted of "an electron which has assumed a cloak of darkness in the form of sufficient positive electricity to neutralize its charge." Many of his ideas were initially proposed in letters to British physicist Ernest Rutherford, a correspondence that sustained him throughout what historians now call the "BraggBarkla Controversy."

Lawrence Bragg was only 22 at the time of his "brainwave." He had studied mathematics at Trinity College and again at Adelaide University before his father convinced him to add some formal physics study to his curriculum. Returning to Trinity College upon his father's transfer to Leeds, Lawrence worked in the Cavendish Laboratory under J.J. Thomson and listened as the eminent physicist lectured on the wave nature of x-rays. A fellow student in the scientific society at Cambridge read a paper concerning the packing of atoms as spheres in crystal structures, which led Lawrence to the realization that atoms in crystals were arranged in parallel planes. It was the combination of these ideas during his walk in 1912 that gave him the insight into von Laue's x-ray photographs and led to the determination of the crystal structures of $\mathrm{KCl}$ and $\mathrm{NaCl}$. He soon developed the mathematical expression that defines the conditions under which reflected waves interfere constructively, aptly named Bragg's Law:

$$
n \lambda=2 d \sin \theta,
$$

where $n$ is an integer, $\lambda$ is the wavelength of the incident radiation, $d$ is the interplanar spacing, and $\theta$ is the angle of incidence of the radiation. The schematic illustration of these factors can be accessed at Web site www.britannica. com/eb/art?id=30656\&type=A.

In order to confirm that the diffracted waves were indeed x-rays, William Bragg constructed the first x-ray spectrometer with his assistant Jenkinson at Leeds. 
Radiation from an x-ray tube was collimated by passing through a slit, then through the sample crystal, which was mounted on a pedestal. The ionization chamber that served as the detector was mounted on an arm that could rotate about the crystal, and the angles of reflection were read from a scale on the sample pedestal. A Wilson gold-leaf electroscope measured the charge of the ionization chamber. Whereas the von Laue photographs could take up to $20 \mathrm{~h}$ to produce, with frequent stops to cool the $x$-ray tube, William Bragg's ionization technique made the analysis faster and more accurate, since the angles between the crystal and the diffracted beam could be measured for each reflection. Lawrence had been trying to deduce the structure of diamond at the time from the von Laue photographs, with no luck. However, when analyzed in the x-ray spectrometer, the diamond quickly yielded its secrets.

It was later concluded that both William
Bragg and Charles Barkla were right in their early dispute; their differences arose from choices in experimental techniques and their own preconceptions. Barkla, convinced of the wave nature of $x$-rays, set up polarization experiments that confirmed his theories. Bragg, having experimented with $\alpha$ particles, conducted experiments designed to detect the preferred forwardscattering effect of particles. Both found what they were looking for. Albert Einstein's paper on the photoelectric effect in 1905, with its characteristic equation $E=$ hv (where $E$ is the energy of a photon, $h$ is Planck's Constant, and $v$ is the frequency of the radiation) predicted this dual wave-particle nature of radiation and matter, but it was not generally understood in 1912. Later in life, William Bragg frequently explained to listeners, "Physicists use the wave theory on Mondays, Wednesdays, and Fridays, and the particle theory on Tuesdays, Thursdays, and Saturdays."

William Bragg devoted himself to sub- marine detection during World War I, and took up investigations of organic crystals after the war. He was knighted in 1920, made director of the Royal Institution in 1923, and president of the Royal Society in 1935. He died in London in 1942. Following his father's path, Lawrence Bragg was knighted in 1941, and elected director of the Royal Institution in 1954. He retired in 1966 and died in Ipswich in 1971.

TIM PALUCKA

FOR FuRTHER READING: G.M. Caroe, William Henry Bragg, 1862-1942 (Cambridge University Press, Cambridge, 1978); Sir Lawrence Bragg, The Development of X-Ray Analysis (Hafner Press, New York, 1975); and Sir Lawrence Bragg, The Start of X-Ray Analysis (published for the Nuffield Foundation by Longmans, London, 1967). As mentioned in the article, a schematic illustration of Bragg's Law can be accessed on the World Wide Web at www.britannica. com/eb/art?id=30656\&type $=$ A. 